
estimates of climate at both specific locations of interest and in the form of regular grids. Projected climate change is another motivating factor in the development of these products. Spatial models of projected future climate allow these changes to be mapped, regional impacts to be assessed, and adaptation measures to be developed.

In response to the need for spatial climate data, researchers at Natural Resources Canada's Canadian Forest Service (CFS), the Australian National University (ANU), Environment Canada (EC), and the National Oceanic and Atmospheric Administration (NOAA) have collaborated to develop a wide range of spatial climate models. These models cover both Canada and the continental United States for a wide variety of climate variables, at time steps from monthly to daily, and across a range of spatial resolutions. The initial motivation in developing the models was to address forestry-related issues; however, many agencies and researchers have since used them in a variety of applications. Here we discuss the general method used to generate the models, with particular attention paid to the assessment of their predictive accuracy (as opposed to model fit), and describe the array of products available and how they may be accessed. We also briefly describe some of the wider applications of these models and outline expected further developments. Our overall intent is to contribute to the wider awareness of these products.

CLIMATE DATA. All spatial climate modeling begins with, and ultimately depends on, data from meteorological stations. In Canada, these data mostly

Affiliations: McKenney, Papadopol, Lawrence, Pedlar, and CAMBelL-Canadian Forest Service, Natural Resources Canada, Sault Ste. Marie, Ontario, Canada; HutCHINsON-Fenner School of Environment and Society, Australian National University, Canberra, Australian Capital Territory, Australia; MILEWSKAClimate Research Division, Environment Canada, Toronto, Ontario, Canada; HoPKINSON-Custom Climate Services, Regina, Saskatchewan, Canada; PRICE-Canadian Forest Service, Natural Resources Canada, Edmonton, Alberta, Canada; OWEN-NOAA/ National Climatic Data Center, Asheville, North Carolina CORRESPONDING AUTHOR: Dan McKenney, Canadian Forest Service, 1219 Queen Street East, Sault Ste. Marie, ON P6A 2E5, Canada

E-mail: dan.mckenney@nrcan-rncan.gc.ca

The abstract for this article can be found in this issue, following the table of contents.

DOI:10.1175/BAMS-D-10-3132.1

In final form 14 June 2011

(C20II American Meteorological Society originate from Environment Canada, although there are other station networks available in some regions (e.g., summer fire weather stations). In the United States, NOAA's National Climatic Data Center (NCDC) is the largest provider of climate data. Both of these agencies provide a wide variety of data products that have been error checked to varying degrees. Indeed, data quality is often taken for granted but considerable effort is expended in both Canada and the United States to provide consistent, long-term, reference-quality climate data and weather records (e.g., see Hutchinson et al. 2009; Hopkinson et al. 2011; Karl and Williams 1987; Vose et al. 2003; Peterson and Owen 2005; Menne et al. 2009, 2010). Despite extensive quality control measures, however, there can often be errors or inconsistencies that make it past the checks as well as inaccuracies inherent to the instrumentation used to measure the various climate metrics recorded at each station (i.e., measurement errors). For these reasons, among others, it must be remembered that spatial climate models are at best an approximation of actual climate. Both modelers and users should be acutely aware of data quality issues (e.g., Daly 2006; Hopkinson et al. 2011).

Another important data issue, particularly for disciplines such as forestry, which require historical climate records, is the variation in the number of climate stations through time and space. Prior to about 1930, there were very few weather stations in Canada, and far northern regions continue to be underserviced in the modern era [see McKenney et al. (2006a) for maps illustrating the varying number of stations over time]. The situation has been much better for the United States, though some data gaps exist (Guttman and Quayle 1996; Kunkel et al. 2005). Data deficiencies should be kept in mind, especially when using climate models covering older periods and/or northern regions. Error diagnostics and assessments of predictive error are discussed below. These are essential for detecting and correcting data errors and model deficiencies, and for providing users with reliable measures of predictive accuracy of the fitted climate models.

\section{GENERATING CLIMATE MODELS AND}

MAPS. All the climate models reported here have been generated using thin-plate smoothing splines, as implemented in the ANUSPLIN climate modeling software (e.g., Hutchinson 2011). The earliest applications of thin-plate smoothing splines were described by Wahba and Wendelberger (1980) and Hutchinson and Bischof (1983), but the methodology has been further developed into an operational climate mapping 
tool at the ANU over the last 20 years. ANUSPLIN has become one of the leading technologies in the development of climate models and maps, and has been applied in North America and many regions around the world (e.g., New et al. 2002; Hijmans et al. 2005; Rehfeldt 2006; Hutchinson et al. 2009). As documented in Daly (2006), ANUSPLIN belongs to the class of climate interpolation methods that can account for spatially varying dependences on elevation, a dominant predictor that is closely aligned with many controlling physical factors. A key strength of the ANUSPLIN method, in contrast to local regression methods, is its dependence on all the data (i.e., every data point observed for a single time slice contributes to the model fitted to minimize the generalized cross validation). This permits the robust and stable determination of dependencies on the predictor variables, particularly in data sparse, high-elevation regions.

ANUSPLIN is essentially a multidimensional "nonparametric" surface fitting method that has been found particularly well suited to the interpolation of various climate parameters, including daily maximum and minimum temperature, precipitation, and solar radiation. The underlying mathematics have been described in Wahba (1990) and Hutchinson (2011) (and references therein), so here we describe only the basic elements. The formal relationship between smoothing spline and kriging methods is well known (Matheron 1981; Dubrule 1983) and has been examined in a more practical setting by Hutchinson and Gessler (1994). A general representation for a thin-plate smoothing spline model fitted to $n$ data values $z_{i}$ at positions $x_{i}$ is given by Hutchinson (1995) as

$$
z_{i}=\hat{\mathrm{J}}\left(x_{i}\right)+\varepsilon_{i}(i=1, \ldots, n),
$$

where $f$ is an unknown function to be estimated, subject to a general smoothness condition and matching the $n$ data values $z_{i}$ to within an appropriate degree of error, as represented by the $\varepsilon_{i}$. The $\varepsilon_{i}$ are considered to be random errors (with zero mean) that account for measurement error as well as deficiencies in the spline model, such as local effects below the resolution of the data network.

Contrary to common perception, a multivariate thin-plate smoothing spline is neither a piecewise second- or third-order polynomial nor a tensor product of such. It is in fact a true multivariate generalization of the univariate cubic smoothing spline. This depends on sophisticated numerical methods, as described in Wahba (1990) and implemented in the
ANUSPLIN software, to achieve a computationally efficient solution. A second misconception is that the climate fields interpolated by ANUSPLIN are always smooth and hence incapable of matching strong gradients in the data. In practice, strong horizontal gradients are often associated with strong gradients in elevation, so a smooth dependence on elevation can effectively represent such strong climatic gradients. However, where there are minimal observations (i.e., station data), smoothing splines can have difficulty matching strong gradients in the dependency of the climate surface on elevation, as manifested in temperature inversions and across sharp rain shadows.

The parameters for the basic model, along with the amount of data smoothing, are usually estimated by minimizing a diagnostic called the generalized cross validation (GCV). This is normally a reliable measure of the predictive error of the fitted smoothing spline function that is discussed further below. It is calculated by implicitly removing each data point in turn and summing, with appropriate weighting, the square of the difference of each omitted data value from the spline fitted to all other data points. When fitting precipitation fields, it is currently recommended to apply a square root transformation to the precipitation in the surface fitting procedure to reduce skewness in the precipitation data (Hutchinson 1998; Hutchinson et al. 2009). This equilibrates the observed variability in precipitation between small and large values. The effectiveness of this transformation has been confirmed by its ability to allow the detection of subtle observation errors, such as missing precipitation values recorded as zero in low-rainfall areas, a relatively common data error. ANUSPLIN automatically corrects for the small negative bias that results from this transformation (Hutchinson 2011).

In most standard applications, the $x_{i}$ represents longitude, latitude, and appropriately scaled elevation. Hutchinson (1995) has shown that it is appropriate to multiply elevation by a factor of 100 in relation to horizontal position when using trivariate splines to model precipitation. This agrees with the accepted relative horizontal and vertical distance scales of atmospheric dynamics (Daley 1991) and underlines the dominant impact of elevation in these spatial models. Sharples et al. (2005) have demonstrated that the optimal spatial resolution of this elevation dependence is around $5-10 \mathrm{~km}$, in line with previous studies. While the trivariate model is robust and well aligned with the controlling physical processes, the model, as indicated above, is still subject to the limitations imposed by sparse data networks. Thus, for example, the spline model has been found to 
be deficient in representing precipitation gradients across the remote highlands of Bolivia and northern Peru, where very few long-term climate stations have been established (Killeen et al. 2007). Furthermore, comparison with satellite temperature data in western Canada suggested limitations to the spline approach in relation to certain land cover types, very high elevations, and large water bodies, where climate stations were few and unrepresentative; outside these data sparse areas, the models estimated well (Bussières and Milewska 2010).

Coastal temperature gradients, temperature inversions caused by cold-air pooling, and slope and aspect effects on precipitation (e.g., rain shadows) are well known in parts of North America, especially in coastal and mountainous areas (cf. Daly et al. 2008). Previous work has been done to represent these effects in ANUSPLIN models by incorporating additional predictors, such as distance from large water bodies and terrain variables such as slope and aspect (Hutchinson 1995). However, these effects are not simulated explicitly in our North American climate models. The incorporation of additional local predictors has been a particular challenge in Canada, where the number of data points representing these areas is very small. This is especially true in northern Canada, which contains just 5\% of the available Canadian station network (Hutchinson et al. 2009). However, it should be noted that additional predictors, even when robustly calibrated, do not always improve the predictive accuracy of statistical models. Thus, Jarvis and Stuart (2001) found that more sophisticated interpolators, such as kriging and splines, required fewer additional predictors than less sophisticated methods to interpolate daily temperature, with a partial spline dependence on elevation yielding the best results.

ANUSPLIN can be configured in various ways. For example, the software can incorporate linear submodels to form a partial spline (Hutchinson 1991; Jarvis and Stuart 2001). Such analyses have been used to incorporate physical, process-based topographic influences for interpolating monthly evapotranspiration and pan evaporation data (McVicar et al. 2007). ANUSPLIN can also support exact interpolation through the climate station data values. Exact interpolation essentially assumes no error in the station data and can result in steep, questionable gradients between stations. Nevertheless, in situations where data are limited, and the statistical relationship between the climate variable of interest and the predictor variables is poorly supported, the capability to modify the structural form and nature of the final fitted function has proven to be useful.
Importantly for practical applications, the spline models can be easily resolved to any location (e.g., forest research plots, plantation sites, vegetation survey locations, farms) by providing site values for each independent variable-typically latitude, longitude, and elevation. This is perhaps a somewhat subtle point-with longitude and latitude as the independent variables, the models are spatially continuous. Elevation values, if not known, can be estimated via readily available digital elevation models (DEMs). Maps are generated by supplying a regular grid of the independent variables - usually in the form of a DEM. Most of our standard Internet map products make use of a 300-arc-second-resolution (approximately $10 \mathrm{~km}$ ) DEM that was developed from Canada's 1:250,000 National Topographic Series topographic data (see Lawrence et al. 2008 for details) and the Global 30 Arc-Second Elevation Data Set (GTOPO30) DEM available from the U.S. Geological Survey (USGS; see http://eros.usgs.gov/\#/Find_Data/Products_and Data_Available/gtopo30_info). Higher-resolution maps have also been generated for mountainous areas and other locations where analysts have particular needs-catchment hydrology studies being one relevant example. Given the increase in computing power and data storage capacities, higher-resolution grids are now much more feasible, although for some variables (e.g., precipitation) there is a limit to how much extra information finer topographic (DEM) resolutions can provide (Sharples et al. 2005). Many of our web-accessible maps (described below) are variably resolved at scales appropriate for user-defined domains.

CLIMATE CHANGE MODELS. We have also generated a suite of climate change products [see McKenney et al. (2006b) for full details; Joyce et al. 2011; Price et al. 2011] using data made available following the Intergovernmental Panel on Climate Change's (IPCC) Third and Fourth Assessment Reports (Houghton et al. 2001; Alley et al. 2007). The monthly time series of surface estimates for certain desirable variables, as projected by four general circulation models (GCMs) for different forcing scenarios of future greenhouse gas emissions [as described in Nakicenovic and Swart (2000)], were downloaded from publicly accessible Internet sites. These climate change projections are necessarily very coarse in nature, with grid spacings of $150 \mathrm{~km}$ or greater, and hence generally require "downscaling" to a more relevant resolution to be useful for impacts studies. In our case, the raw GCM outputs were interpolated after converting them to anomalies relative to the 
1961-90 period (as simulated by the same GCM). These anomaly surfaces have also been integrated at the locations of more than 7,000 climate stations in the United States and Canada, and the predicted changes at these locations added to the 1961-90 station normals. This has provided a network of stations with projected climate values that incorporated both established site-to-site variation in climate as well as the broad-scale average changes predicted by the GCMs. Besides interpolating these models of future climate for each month of each year through to 2100 (Price et al. 2004), we have also generated average changes for three future periods (2011-40, 2041-70, and 2071-2100) (McKenney et al. 2006b; see also Joyce et al. 2011; Price et al. 2011).

CLIMATE PRODUCTS. Table 1 provides an overview of the "primary" climate surfaces currently completed. Many of the variables listed in Table 1 have been modeled at a number of different scales and time steps. Daily minimum and maximum temperature and precipitation are primary

\begin{tabular}{|c|c|c|c|c|c|}
\hline Parameter & Units & Time step ${ }^{a}$ & Type & Period covered & Area coveredc \\
\hline \multirow{5}{*}{$\begin{array}{l}\text { Minimum and maximum } \\
\text { temperature }\end{array}$} & \multirow{5}{*}{${ }^{\circ} \mathrm{C}$} & \multirow{2}{*}{$\mathrm{m}$} & $\mathrm{n}$ & $1931-60,196|-90| 97 \mid-2000$, & CA, NA \\
\hline & & & $\mathrm{h}$ & $190 \mid-2008$ & $\mathrm{CA}, \mathrm{NA}$ \\
\hline & & \multirow{2}{*}{$w$} & $n$ & $196|-90,197|-2000$ & CA \\
\hline & & & $\mathrm{h}$ & $196 \mid-2003$ & CA \\
\hline & & $d$ & $\mathrm{~h}$ & $1950-2008$ & CA \\
\hline \multirow{5}{*}{ Precipitation } & \multirow{5}{*}{$\mathrm{mm}$} & \multirow{2}{*}{$\mathrm{m}$} & $\mathrm{n}$ & $1931-60,1961-90,197 \mid-2000$ & CA, NA \\
\hline & & & $\mathrm{h}$ & $190 \mid-2008$ & CA, NA \\
\hline & & \multirow{2}{*}{ w } & $\mathrm{n}$ & $1961-90,197 \mid-2000$ & CA \\
\hline & & & $\mathrm{h}$ & $|96|-2003$ & CA \\
\hline & & $d$ & $\mathrm{~h}$ & 1950-2008 & CA \\
\hline Solar radiation & $\mathrm{MJ} \mathrm{m^{-2 }}$ & $\mathrm{m}$ & $\mathrm{n}$ & $196 \mid-1990$ & CA, NA \\
\hline Photovoltaic potential & $\mathrm{MJ} \mathrm{m^{-2 }}$ & $\mathrm{m}$ & $\mathrm{n}, \mathrm{h}$ & $197 \mid-1994$ & CA \\
\hline Sunshine & $\mathrm{h}$ & $\mathrm{m}$ & $\mathrm{n}$ & $196|-1990 ;| 97 \mid-2000$ & CA \\
\hline Potential evapotranspiration & $\mathrm{mm}$ & $\mathrm{m}$ & $\mathrm{n}$ & $196|-1990,197|-2000$ & CA, NA \\
\hline Climate moisture index & $\mathrm{cm}$ & $\mathrm{m}$ & $\mathrm{n}$ & $1961-1990,197 \mid-2000$ & CA, NA \\
\hline Relative humidity & $\%$ & $\mathrm{~m}$ & $\mathrm{n}$ & $196 \mid-1990$ & CA, NA \\
\hline Vapor pressure & $\mathrm{kPa}$ & $\mathrm{m}$ & $\mathrm{n}$ & $1961-1990$ & CA \\
\hline Evaporation (pan and lake) & $\mathrm{mm}$ & $\mathrm{m}, \mathrm{w}$ & $\mathrm{n}, \mathrm{h}$ & $196 \mid-1990$ & CA \\
\hline \multirow{2}{*}{$\begin{array}{l}\text { Extreme minimum and } \\
\text { maximum temperature }\end{array}$} & \multirow{2}{*}{${ }^{\circ} \mathrm{C}$} & $\mathrm{a}, \mathrm{m}$ & $\mathrm{n}$ & $1961-1990,197 \mid-2000$ & NA \\
\hline & & $\mathrm{a}, \mathrm{m}$ & $\mathrm{h}$ & $|96|-2000$ & NA \\
\hline Frost-free days & $d$ & a & $\mathrm{n}$ & $196 \mid-1990$ & CA \\
\hline Avg wind speed & $\mathrm{km} \mathrm{h}^{-1}$ & $\mathrm{~m}$ & $\mathrm{n}$ & $196 \mid-1990$ & CA, NA \\
\hline Maximum wind gust & $\mathrm{km} \mathrm{h}^{-1}$ & $\mathrm{~m}$ & $\mathrm{n}$ & $196|-1990,197|-2000$ & CA \\
\hline Rainfall & $\mathrm{mm}$ & $\mathrm{m}$ & $\mathrm{n}$ & $|93|-60,|96|-90,|97|-2000$ & CA \\
\hline \multirow{2}{*}{ Snow depth } & \multirow{2}{*}{$\mathrm{cm}$} & \multirow{2}{*}{$\mathrm{m}$} & $\mathrm{n}$ & $1961-90,1971-2000$ & CA \\
\hline & & & $\mathrm{h}$ & $1955-2008$ & \\
\hline
\end{tabular}

a The time unit of the climate model: $a=$ annual, $m=$ monthly, $w=$ weekly, and $d=$ daily.

b The type of climate model: $\mathrm{n}=$ normal (i.e., long-term average) and $\mathrm{h}=$ historical (i.e., models generated for each year over a given period).

c $\mathrm{CA}=$ Canada; NA = Canada and the United States.

d As defined by Hogg (1997). 
variables that are used in many applications and, as such, considerable effort has gone into summarizing them in various ways. For example, daily minimum and maximum temperature surfaces are available in the form of i) monthly averages for a variety of 30-yr "normal" periods (e.g., 1901-30, 1931-60, 1961-90), ii) monthly averages for each year over the period 1901-2008, and iii) daily values for each day over the period 1950-2007. Similar products are available for precipitation. The remainder of the

\begin{tabular}{|c|c|}
\hline Variable & Description \\
\hline Annual mean temperature & Avg of mean monthly temperatures \\
\hline Mean diurnal range & Avg of monthly temperature ranges \\
\hline Isothermality & Variable $2 \div$ variable 7 \\
\hline Temperature seasonality & $\begin{array}{l}\text { Standard deviation of monthly-mean temperature estimates expressed as a } \\
\text { percent of their mean }\end{array}$ \\
\hline Max temperature of warmest month & Highest monthly maximum temperature \\
\hline Min temperature of coldest month & Lowest monthly minimum temperature \\
\hline Temperature annual range & Variable 5 - variable 6 \\
\hline Mean temperature of wettest quarter & Avg temperature during 3 wettest months \\
\hline Mean temperature of driest quarter & Avg temperature during 3 driest months \\
\hline Mean temperature of warmest quarter & Avg temperature during 3 warmest months \\
\hline Mean temperature of coldest quarter & Avg temperature during 3 coldest months \\
\hline Annual precipitation & Sum of monthly precipitation values \\
\hline Precipitation of wettest month & Precipitation of the wettest month \\
\hline Precipitation of driest month & Precipitation of the driest month \\
\hline Precipitation seasonality & $\begin{array}{l}\text { Standard deviation of the monthly precipitation estimates expressed as a } \\
\text { percent of their mean }\end{array}$ \\
\hline Precipitation of wettest quarter & Total precipitation of 3 wettest months \\
\hline Precipitation of driest quarter & Total precipitation of 3 driest months \\
\hline Precipitation of warmest quarter & Total precipitation of 3 warmest months \\
\hline Precipitation of coldest quarter & Total precipitation of 3 coldest months \\
\hline Growing season start & Julian day number at start of growing season \\
\hline Growing season end & Julian day number at end of growing season \\
\hline Growing season length & Length of growing season (days) \\
\hline Total precipitation period I & Total precipitation 3 weeks prior to growing season \\
\hline Total precipitation period 2 & Total precipitation during first 6 weeks of growing season \\
\hline Total precipitation period 3 & Total precipitation during the growing season \\
\hline Total precipitation period 4 & Variable 25 - variable 24 \\
\hline Growing degree days period I & Degree days (above $5^{\circ} \mathrm{C}$ ) for 3 weeks prior to growing season \\
\hline Growing degree days period 2 & Degree days (above $5^{\circ} \mathrm{C}$ ) for first 6 weeks of growing season \\
\hline Growing degree days period 3 & Degree days (above $5^{\circ} \mathrm{C}$ ) for growing season \\
\hline Growing degree days period 4 & Variable 29 - variable 28 \\
\hline Annual minimum temperature & Overall average of monthly average minimum temperatures \\
\hline Annual maximum temperature & Overall average of monthly average maximum temperatures \\
\hline Mean temperature period 3 & Average temperature during growing season \\
\hline Temperature range period 3 & $\begin{array}{l}\text { Highest maximum temperature minus lowest minimum temperature during } \\
\text { growing season }\end{array}$ \\
\hline
\end{tabular}


variables in Table 1 have been developed for specific applications and generally cover shorter periods and fewer time steps.

The temperature and precipitation variables can also be used to calculate a suite of "bioclimatic" variables (Table 2). These variables summarize temperature and precipitation in ways that are potentially important to plants and animals and are arguably more intuitive for some purposes. They include classic temperature-based bioclimatic indices, such as growing season length, growing degree-day sums, minimum temperature of the coldest month, and annual mean temperature, which are often used as input to process-based models of ecosystem dynamics (e.g., Sitch et al. 2003) as well as numerous agricultural crop models. These variables are available for both 30-yr normal periods and historical monthly time steps. For our climate change work, we generated spatial models of future climate based on a variety of GCMs and emissions scenarios (Table 3), including three future normal periods for the bioclimatic summary variables listed in Table 2 as well as temperature and precipitation, as previously noted.

More than 60,000 of our climate models can be viewed in map format online (http://cfs.nrcan.gc.ca /projects/3?lang=en_CA). This number does not include the historical daily climate models because their file size prohibits rapid interactive mapping (i.e., there are more than 50,000 daily models alone). The Web mapper makes use of MapServer, an open-source project to support spatial mapping on the Internet (see http://mapserver.org). These data are managed in an Oracle Database framework that supports large dataset management applications (www.oracle.com /index.html). Though the Web mapping system is not a geographic information system (GIS) per se, it does have some GIS functionality, such as data layer selection, zoom capabilities, and a simple query tool. A recent feature is the option to download model estimates for user-supplied locations. The volume of customized data requests has grown significantly over time, and this new capacity should facilitate the use of these climate models while easing the burden of responding to data requests. It is currently not possible to download gridded data directly from the website. However, for those using the OpenGIS data protocols, maps can be drawn in GIS using the Web Map Service protocol. For the time being, gridded data requests can be made by contacting the corresponding author.

HOW GOOD ARE THE MODELS? Our climate models are assessed for predictive accuracy and bias using a variety of metrics. Several measures of model quality are also provided as standard output with each ANUSPLIN run. The signal, given by the trace of the influence matrix (Wahba 1990), indicates the complexity of the surface and varies between a small positive integer and the number of weather stations used in each model. Hutchinson and Gessler (1994) suggest that the signal should be no more than about half the number of data points. Models with such signals tend to be more robust and reliable in datasparse regions. This is particularly important for applications in forested regions, where weather station coverage is often sparse. The GCV described above is also normally a reliable measure of the predictive capacity of the models. Its main weakness is that it can lead to undersmoothing of noisy data when there is significant short-range correlation in the data (Hutchinson and Gessler 1994). It can also be biased when the data network has uneven density. The analysis by Hutchinson (1998) indicates that in the
TABLE 3. GCMs, versions, and emissions scenarios for which surfaces of North American future climate have been generated.

\begin{tabular}{|l|c|c|c|}
\hline \multicolumn{1}{|c|}{ GCM } & Version* & Scenario & Period** \\
\hline $\begin{array}{l}\text { Canadian Centre for Climate } \\
\text { Modelling and Analysis Coupled } \\
\text { GCM (CGCM) }\end{array}$ & 2.0 & A2, B2 & $\mid 900-2100$ \\
\hline $\begin{array}{l}\text { Commonwealth Scientific and } \\
\text { Industrial Research Organisation } \\
\text { (CSIRO) }\end{array}$ & 2.0 & A2, AIB, BI & $|96|-2100$ \\
\hline $\begin{array}{l}\text { National Center for Atmospheric } \\
\text { Research (NCAR) }\end{array}$ & PCM & A2, B2 & $|96|-2100$ \\
\hline $\begin{array}{l}\text { Hadley Centre Coupled Model } \\
\text { (HadCM) }\end{array}$ & 3.0 & A2, B2 & $\mid 950-2099$ \\
$\begin{array}{l}\text { Center for Climate System Research } \\
\text { Model for Interdisciplinary Research } \\
\text { on Climate (MIROC) }\end{array}$ & 3.2 & A2, AIB, BI & $\mid 961-2100$ \\
\hline
\end{tabular}

* PCM = Parallel Climate model; CCSM3 = Community Climate System Model, version 3.

** Raw GCM data were obtained for the period listed; future projections are for three future normal periods $(20 I I-40,204 I-70,207 I-2 I 00)$ and various other time steps of interest. 
precipitation context, short-range correlation operates over distances less than $10 \mathrm{~km}$. Thus, short-range correlation has limited impact on relatively sparse datasets. Bias due to uneven network density can be assessed by calculating predictive errors at spatially representative locations withheld from the fitting procedure. McKenney et al. (2006a) and Hutchinson et al. (2009) have verified the accuracy of GCV in Canada-wide analyses using explicitly withheld data that equisampled the longitude, latitude, and vertically exaggerated elevation space covered by the data networks. The GCVs were closer to the withheld error statistics for temperature, which is more reliably estimated from limited data networks than is precipitation. McKenney et al. (2008) also demonstrated good agreement between GCVs and spatially representative withheld error statistics for spatial analyses of solar radiation. The two error statistics also agreed in their relative assessments of predictive accuracy of three different spline model formulations, confirming the ability of GCV to discriminate between different models without the need for explicitly withholding test data.

Hutchinson et al. (2009) provided a comprehensive withheld data assessment of their fitted daily temperature and precipitation models, by calculating the mean error (i.e., bias) and mean absolute error (i.e., accuracy) of the differences between the estimated values and the recorded withheld values at specific spatially representative locations. This analysis showed that the predictive errors generated for daily thin-plate smoothing spline interpolations compared well with those reported for other methods and locations using denser data networks. Errors in estimating daily rainfall occurrence of around $17 \%$ compared well with the one other study for North America where this statistic was reported. Daily rainfall occurrence is a critical issue in, for example, modeling crop disease (e.g., Kang et al. 2010). A recent revision of this analysis using data corrected for time of observation further reduced these predictive errors by about $15 \%$ and $22 \%$ for the summary temperature and precipitation residuals, respectively (Hopkinson et al. 2011), further underlining the importance of data quality issues.

Table 4 summarizes average withheld error estimates for our temperature and precipitation models across spatially representative locations at the monthly normal, historical monthly, and historical daily time steps. Errors associated with the normal surfaces are quite small, reflecting the greater spatial coherence of monthly normals. The corresponding values in Table 4 are similar to those reported by Price et al. (2000) and Daly et al. (2008). They are

\begin{abstract}
TABLE 4. Mean absolute (i.e., accuracy) and mean (i.e., bias) withheld errors associated with spatial models of temperature and precipitation. Fifty spatially representative withheld stations were used to test the daily [see Hutchinson et al. (2009) for details] and monthly normal (Hopkinson et al. 20II, manuscript submitted to J. Appl. Meteor. Climatol.) models that cover Canada; 200 spatially representative withheld stations were used to test the monthly historical models that cover Canada and the United States (see McKenney et al. 2006a for details).
\end{abstract}

\begin{tabular}{|c|c|c|c|c|c|c|}
\hline Parameter & Units & Time step ${ }^{a}$ & Model type & Period & $\begin{array}{c}\text { Mean } \\
\text { absolute error }\end{array}$ & Mean error \\
\hline \multirow{3}{*}{$\begin{array}{l}\text { Minimum } \\
\text { temperature }\end{array}$} & \multirow{3}{*}{${ }^{\circ} \mathrm{C}$} & $\mathrm{m}$ & $\mathrm{n}$ & $197 \mid-2000$ & 0.6 & 0.04 \\
\hline & & $\mathrm{m}$ & $\mathrm{h}$ & 1950-2000 & 1.3 & 0.02 \\
\hline & & $d$ & $\mathrm{~h}$ & $1961-1990$ & 1.6 & -0.02 \\
\hline \multirow{3}{*}{$\begin{array}{l}\text { Maximum } \\
\text { temperature }\end{array}$} & \multirow{3}{*}{${ }^{\circ} \mathrm{C}$} & $\mathrm{m}$ & $\mathrm{n}$ & $197 \mid-2000$ & 0.4 & 0.23 \\
\hline & & $\mathrm{m}$ & $\mathrm{h}$ & $1950-2000$ & 0.9 & 0.05 \\
\hline & & $d$ & $\mathrm{~h}$ & $1961-1990$ & 1.1 & 0.07 \\
\hline \multirow{3}{*}{ Precipitation } & \multirow{3}{*}{$\%$} & $\mathrm{~m}$ & $\mathrm{n}$ & $197 \mid-2000$ & 6.7 & -2.30 \\
\hline & & $\mathrm{m}$ & $\mathrm{h}$ & 1950-2000 & 30.3 & 2.50 \\
\hline & & d & $\mathrm{h}$ & $196 \mid-1990$ & $8.9^{c}$ & $-1.60^{c}$ \\
\hline
\end{tabular}

a The time unit of the climate model: $\mathrm{m}=$ monthly and $\mathrm{d}=$ daily.

b The type of climate model: $\mathrm{n}=$ normal (i.e., 30-yr average) and $\mathrm{h}=$ historical (i.e., models generated for each time step over a given period).

' Errors associated with daily precipitation models are from annual totals of daily values averaged over withheld stations for the stated period (following Thornton et al. 1997). 
not much larger than the measurement error that can be attributed to the recording instruments. The historical monthly errors are larger, reflecting the challenges of modeling shorter time steps, with monthly temperature errors approximately twice the monthly normal temperature errors. The daily models have slightly larger errors for temperature. However, assessing errors associated with daily precipitation models is problematic (Thornton et al. 1997); thus, we follow the convention of summing daily values to annual totals. Models with shorter time steps are generally expected to have larger errors because they are attempting to capture phenomena that are much more variable in space and time. For example, convective rainfall events often occur over a limited area and can be easily missed by station networks. Thus, while daily models may describe daily temperature extremes reasonably well, they have limited accuracy in describing daily precipitation extremes (Hutchinson et al. 2009). For many applications, the key information required for daily precipitation extremes consists of statistics describing overall likelihood, which are more accurately described by interpolating the key parameters describing these statistics rather than inferring the statistics from individually interpolated daily values. Models using other approaches and additional predictors, such as radar rainfall data (e.g., Haberlandt 2007; Overeem et al. 2009), climate model outputs, and detailed topographic analyses (Böhner 2005), have the potential to further improve accuracy; although, as noted above, additional predictors do not always improve overall predictive accuracy.

USAGE AND APPLICATION. These climate products have been applied in a number of forestrelated areas, such as assessing plant hardiness (McKenney et al. 2007a), climate change impacts on forest resources (McKenney et al. 2007b; Price and Scott 2006), nonindigenous species modeling (Venier et al. 1998; Yemshanov et al. 2009), forest productivity modeling (McKenney and Pedlar 2003; Yemshanov et al. 2007), and seed movement (McKenney et al. 2009). A variety of users from academic institutions and government agencies have applied the data to a range of other topics, including wildlife research (Chu et al. 2008), human health and welfare (McLeman et al. 2010), crop yields (Pearson et al. 2008; Cabas et al. 2010), and photovoltaic energy production (McKenney et al. 2008).

\section{CONCLUSIONS AND FUTURE DIREC-}

TIONS. Spatial climate modeling is an ongoing task, as source datasets change in coverage and quality (e.g., Canadian station numbers have been declining in recent years) and as new applications and methods evolve. In addition to continuously updating and improving existing models, there are many climate variables and time steps for which models could be generated. Here we outline several projects that will be a focus in the near future.

Historical daily climate models provide estimates of past daily temperature and precipitation over a selected period. Such data are particularly valuable as input for models that simulate processes such as plant growth, fire severity, and plant phenology. We currently have daily models that cover the period 1950-2007 for Canada only (Hutchinson et al. 2009). In collaboration with Environment Canada and NOAA's NCDC in the United States, we are in the process of generating North American-wide daily models for this same period and possibly for earlier decades where the data allow. These models will employ datasets that correct for issues such as disparities in "climate day" definitions and recording times between the U.S. and Canadian networks.

Visitors to our website (http://cfs.nrcan.gc.ca /subsite/glfc-climate) are currently able to view maps and download climate values for a set of user-supplied locations. In the future, we hope to launch a function that will allow users to download customized gridded data as well. For simple requests, this will eliminate the need for users to contact us directly. For more complex requests (e.g., involving spatial resolutions not available from the website), users will still need to contact the corresponding author. Another planned enhancement to the website involves the addition of detailed daily summaries. This function would allow users to obtain graphical and tabular summaries of historical temperature and precipitation values for any given location.

There can be a significant lag between when the time measurements are recorded at meteorological stations and when quality-controlled data are made available to the public. We plan to continue to update our models as new station data are made available. For example, when the 2010 records are available, we will generate new normals for the 1981-2010 period. The fifth IPCC report is due out in 2014 and will likely entail improved and updated climate change products, though certain GCMs and scenarios may be added to our current suite of models prior to that. Finally, the ANUSPLIN package continues to be upgraded. For example, "additive" spline models have been developed that can robustly incorporate spatially varying dependencies on several additional 
independent variables without violating the "curse of dimension" (Sharples and Hutchinson 2004).

In conclusion, there is a growing demand for spatially reliable climate models at a variety of temporal and spatial resolutions. This paper has provided details about our climate models-how they are developed and evaluated, how they can be accessed, and how they will be updated and improved in the near future. Models are most valuable when they are used. We hope this paper raises awareness of our climate models and encourages potential users to visit the website or contact us for further information.

ACKNOWLEDGMENTS. We thank several staff members of Environment Canada and Natural Resources Canada who have supported and encouraged our work over time, including Bill Hogg, Anna Deptuch-Stapf, Robert Morris, Robert Vet, Lucie Vincent, Val Swain, and Bob Stewart. We also thank Marty Siltanen of the Canadian Forest Service for his assistance in generating various climate change products. We also thank the reviewers for their comments and assistance in improving the manuscript.

\section{REFERENCES}

Alley, R., and Coauthors, 2007: Summary for policymakers. Climate Change 2007: The Physical Science Basis, S. Solomon et al., Eds., Cambridge University Press, 1-18.

Böhner, J., 2005: Advancements and new approaches in climate spatial prediction and environmental modelling. Arbeitsber. Geogr. Instituts U Berlin, 109, 49-90.

Cabas, J., A. Weersink, and E. Olale, 2010: Crop yield response to economic, site and climatic variables. Climatic Change, 101, 599-616.

Chu, C., N. E. Jones, N. E. Mandrak, A. R. Piggott, and C. K. Minns, 2008: The influence of air temperature, groundwater discharge, and climate change on the thermal diversity of stream fishes in southern Ontario watersheds. Can. J. Fish. Aquat. Sci., 65, 297-308.

Daley, R., 1991: Atmospheric Data Analysis. Cambridge University Press, 457 pp.

Daly, C., 2006: Guidelines for assessing the suitability of spatial climate data sets. Int. J. Climatol., 26, 707-721.

—, M. Halbleib, J. I. Smith, W. P. Gibson, M. K. Doggett, G. H. Taylor, J. Curtis, and P. P. Pasteris, 2008: Physiographically sensitive mapping of climatological temperature and precipitation across the conterminous United States. Int. J. Climatol., 28, 2031-2064.
Dubrule, O., 1983: Two methods with different objectives: Splines and kriging. Math. Geol., 15, 245-257.

Guttman, N. B., and R. G. Quayle, 1996: A historical perspective of U.S. climate divisions. Bull. Amer. Meteor. Soc., 77, 293-303.

Haberlandt, U., 2007: Geostatistical interpolation of hourly precipitation from rain gauges and radar for a large-scale extreme rainfall event. J. Hydrol., 332, 144-157.

Hijmans, R., S. E. Cameron, J. Parra, P. Jones, and A. Jarvis, 2005: Very high resolution interpolated climate surface for global land areas. Int. J. Climatol., 25, 1965-1978.

Hogg, E. H., 1997: Temporal scaling of moisture and the forest-grassland boundary in western Canada. Agric. For. Meteor., 84, 115-122.

Hopkinson, R. F., D. W. McKenney, E. J. Milewska, M. F. Hutchinson, P. Papadopol, and L. A. Vincent, 2011: Impact of aligning climatological day on gridding daily maximum-minimum temperature and precipitation over Canada. J. Appl. Meteor. Climatol., 50, 1654-1665.

Houghton, J. T., Y. Ding, D. J. Griggs, M. Noguer, P. J. van der Linden, X. Dai, K. Maskell, and C. A. Johnson, Eds., 2001: Climate Change 2001: The Scientific Basis. Cambridge University Press, 881 pp.

Hutchinson, M. F., 1991: The application of thin plate smoothing splines to continent-wide data assimilation. Data assimilation systems: Papers presented at the Second BMRC Modelling Workshop, J. D. Jasper, Ed., Bureau of Meteorology Research Centre Research Rep. 27, 104-113.

—, 1995: Interpolation of mean rainfall using thin plate smoothing splines. Int. J. Geogr. Inf. Syst., 9, 385-403.

_, 1998: Interpolation of rainfall data with thin plate smoothing splines-Part I: Two dimensional smoothing of data with short range correlation. J. Geogr. Inf. Decis. Anal., 2, 153-167.

— cited 2011: ANUSPLIN version 4.3. [Available online at http://fennerschool.anu.edu.au/publications /software/anusplin.php.]

—- and R. J. Bischof, 1983: A new method for estimating the spatial distribution of mean seasonal and annual rainfall applied to the Hunter Valley, New South Wales. Aust. Meteor. Mag., 31, 179-184.

_ , and P. E. Gessler, 1994: Splines-More than just a smooth interpolator. Geoderma, 62, 45-67.

—, D. W. McKenney, K. Lawrence, J. H. Pedlar, R. Hopkinson, E. Milewska, and P. Papadopol, 2009: Development and testing of Canada-wide interpolated spatial models of daily minimum-maximum 
temperature and precipitation for 1961-2003. J. Appl. Meteor. Climatol., 48, 725-741.

Jarvis, C. H., and N. Stuart, 2001: A comparison among strategies for interpolating maximum and minimum daily air temperature. Part II: The interaction between number of guiding variables and the type of interpolation method. J. Appl. Meteor., 40, 1075-1084.

Joyce, L. A., D. T. Price, D. W. McKenney, R. M. Siltanen, P. Papadopol, K. Lawrence, and D. P. Coulson, 2011: High-resolution interpolation of climate scenarios for the continental USA and Alaska derived from General Circulation Model simulations. Rocky Mountain Research Station. Gen. Tech. Rep. RM-263, 87 pp. [Available from L. A Joyce, U.S. Department of Agriculture, Forest Service, Rocky Mountain Research Station, Fort Collins, CO 80526.]

Kang, W. S., S. S. Hong, Y. K. Han, K. R. Kim, S. K. Kim, and E. W. Park, 2010: A Web-based information system for plant disease forecast based on weather data at high spatial resolution. Plant Pathol. J., 26, 37-48.

Karl, T. R., and C. N. Williams Jr., 1987: An approach to adjusting climatological time series for discontinuous inhomogeneities. J. Climate Appl. Meteor., 26, 1744-1763.

Killeen, T. J., M. Douglas, T. Consiglio, P. M. Jørgensen, and J. Mejia, 2007: Dry spots and wet spots in the Andean hotspot. J. Biogeogr., 34, 1357-1373.

Kunkel, K. E., D. R. Easterling, K. Hubbard, K. Redmond, K. Andsager, M. C. Kruk, and M. L. Spinar, 2005: Quality control of pre-1948 cooperative observer network data. J. Atmos. Oceanic Technol., 22, 16911705.

Lawrence, K. M., M. F. Hutchinson, and D. W. McKenney, 2008: Multi-scale digital elevation models for Canada. Great Lakes Forestry Centre Frontline Tech. Note 109, 4 pp.

Matheron, G., 1981: Splines and kriging: Their formal equivalence. Syracuse Univ. Geol. Contrib., 8, 77-95.

McKenney, D. W., and J. H. Pedlar, 2003: Spatial models of site index based on climate and soil properties for two boreal tree species in Ontario, Canada. For. Ecol. Manage., 175, 497-507.

,-- , P. Papadopal, and M. F. Hutchinson, 2006a: The development of 1901-2000 historical monthly climate models for Canada and the United States. Agric. For. Meteor., 138, 69-81.

- D. T. Price, P. Papadapol, M. Siltanen, and K. M. Lawrence, 2006b: High resolution climate change scenarios for North America. Great Lakes Forestry Centre Frontline Tech. Note 107, 5 pp.
—, J. H. Pedlar, K. Lawrence, K. Campbell, and M. F. Hutchinson, 2007a: Beyond traditional hardiness zones: Using climate envelopes to map plant range limits. Bioscience, 57, 929-937.

$-, \ldots, \ldots, \ldots$, and,$- 2007 \mathrm{~b}$ : Potential impacts of climate change on the distribution of North American trees. Bioscience, 57, 939-948.

_, S. Pelland, Y. Poissant, R. Morris, M. F. Hutchinson, P. Papadopol, K. Lawrence, and K. Campbell, 2008: Spatial insolation models for photovoltaic energy in Canada. Sol. Energy, 82, 1049-1061.

— , J. H. Pedlar, and G. O’Neill, 2009: Climate change and forest seed zones: Past trends, future prospects and challenges to ponder. For. Chron., 85, 258-266.

McLeman, R., S. Herold, Z. Reljic, M. Sawada, and D. W. McKenney, 2010: GIS-based modeling of drought and historical population change on the Canadian prairies. J. Hist. Geogr., 36, 43-56.

McVicar, T. R., T. G. Van Niel, L. T. Li, M. F. Hutchinson, X. M. Mu, and Z. H. Liu, 2007: Spatially distributing monthly reference evapotranspiration and pan evaporation considering topographic influences. J. Hydrol., 338, 196-220.

Menne, M. J., C. N. Williams Jr., and R. S. Vose, 2009: The U.S. Historical Climatology Network monthly temperature data, version 2. Bull. Amer. Meteor. Soc., 90, 993-1007.

— - , and M. A. Palecki, 2010: On the reliability of the U.S. surface temperature record. J. Geophys. Res., 115, D11108, doi:10.1029/2009JD013094.

Munang, R., M. Rivington, E. S. Takle, B. Mackey, I. Thiaw, and J. Liu, 2010: Climate information and capacity needs for ecosystem management under a changing climate. Procedia Environ. Sci., 1, 206-227.

Nakicenovic, N., and R. Swart, Eds., 2000: Special Report on Emissions Scenarios. Cambridge University Press, 599 pp.

New, M., D. Lister, M. Hulme, and I. Makin, 2002: A high-resolution data set of surface climate over global land areas. Climate Res., 21, 1-25.

Overeem, A., I., Holleman, and A. Buishand, 2009: Derivation of a 10-year radar-based climatology of rainfall. J. Appl. Meteor. Climatol., 48, 1448-1463.

Pearson, C. J., D. Bucknell, and G. P. Laughlin, 2008: Modelling crop productivity and variability for policy and impacts of climate change in eastern Canada. Environ. Modell. Software, 23, 1345-1355.

Peterson, T. C., and T. W. Owen, 2005: Urban heat island assessment: Metadata are important. J. Climate, 18, 2637-2646.

Price, D. T., and D. Scott, 2006: Project A636: Large scale modelling of Canada's forest ecosystem responses to 
climate change. Final Rep., Climate Change Impacts and Adaptation Program, 53 pp. [Available online at http://adaptation.nrcan.gc.ca/projdb/pdf/116_e .pdf.]

— , D. W. McKenney, P. Papadopol, T. Logan, and M. F. Hutchinson, 2004: High resolution future scenario climate data for North America. Extended Abstracts, 26th Conf. on Agricultural and Forest Meteorology, Vancouver, BC, Canada, Amer. Meteor. Soc., 7.7. [Available online at http://ams.confex.com/ams /AFAPURBBIO/techprogram/paper_78202.htm.]

$\longrightarrow,-$, L. A. Joyce, R. M. Siltanen, P. Papadopol, and K. Lawrence, 2011: High-resolution interpolation of climate scenarios for Canada derived from General Circulation Model simulations. Canadian Forest Service, Northern Forestry Centre Information Rep. NOR-X-421, 104 pp.

Rehfeldt, G. E., 2006: A spline model of climate for the western United States. USDA Forest Service RMRS General Tech. Rep. RMRS-GTR-165, 21 pp.

Sharples, J. J., and M. F. Hutchinson, 2004: Multivariate spatial smoothing using additive regression splines. ANZIAM J., 45, C676-C692.

- - , and D. R. Jellett, 2005: On the horizontal scale of elevation dependence of Australian monthly precipitation. J. Appl. Meteor., 44, 1850-1865.

Sitch, S., and Coauthors, 2003: Evaluation of ecosystem dynamics, plant geography and terrestrial carbon cycling in the LPJ dynamic global vegetation model. Global Change Biol., 9, 161-185.
Thornton, P. E., S. W. Running, and M. A. White, 1997: Generating surfaces of daily meteorological variables over large regions of complex terrain. J. Hydrol., 190, 214-251.

Venier, L. A., A. A. Hopkin, D. W. McKenney, and Y. Wang, 1998: A spatial, climate-determined risk rating for Scleroderris disease of pines in Ontario. Can. J. For. Res., 28, 1398-1404.

Vose, R. S., C. N. Williams Jr., T. C. Peterson, T. R. Karl, and D. R. Easterling, 2003: An evaluation of the time of observation bias adjustment in the U.S. historical climatology network. Geophys. Res. Lett., 30, 2046-2049.

Wahba, G., 1990: Spline Models for Observational Data. CBMS-NSF Regional Conference Series in Applied Mathematics, Vol. 59, Society for Industrial and Applied Mathematics, 169 pp.

— cal methods for variational objective analysis using splines and cross validation. Mon. Wea. Rev., 108, $1122-1143$.

Yemshanov, D., D. W. McKenney, S. Fraleigh, and S. D'Eon, 2007: An integrated spatial assessment of the investment potential of three species in southern Ontario, Canada inclusive of carbon benefits. For. Policy Econ., 10, 48-59.

— - _ J. H. Pedlar, F. H. Koch, and D. Cook, 2009: Towards an integrated approach to modelling the risks and impacts of invasive forest species. Environ. Rev., 17, 163-178. 